\title{
Low Lumbar Multifidus Muscle Status and Bone Mineral Density are Important Risk Factors for Adjacent Segment Disease After Lumbar Fusion-A Case-Control Study
}

\section{Zhaoyang Gong}

Department of Orthopedics, Huashan Hospital, Fudan University , Shanghai

\section{Dachuan Li}

Department of Orthopedics, Huashan Hospital, Fudan University, Shanghai

Fei Zou

Department of Orthopedics, Huashan Hospital, Fudan University , Shanghai siyang Liu

Department of Orthopedics, Huashan Hospital, Fudan University, Shanghai Hongli Wang

Department of Orthopedics, Huashan Hospital, Fudan University , Shanghai xiaosheng Ma ( $\sim$ dr_maxiaosheng@126.com)

Department of Orthopedics, Huashan Hospital, Fudan University, Shanghai

\section{Research Article}

Keywords: Multifidus muscle, Bone mineral density, Adjacent segment disease

Posted Date: March 7th, 2022

DOI: https://doi.org/10.21203/rs.3.rs-1415531/v1

License: (c) (i) This work is licensed under a Creative Commons Attribution 4.0 International License.

Read Full License 


\section{Abstract \\ Background}

The quantity and quality of the paraspinal muscles are important factors that lead to spinal diseases. However, the role of paraspinal muscles in the pathogenesis of adjacent segment disease (ASD) after lumbar fusion surgery is rarely studied. The purpose of the research is to investigate the relationship between paraspinal muscles and ASD.

\section{Methods}

33 patients with ASD were included, and 33 controls without ASD were matched according to the basic demographic information. Cross-sectional images of the paraspinal muscles at each intervertebral disc level (L1-S1) before the first operation were analyzed, and the cross-sectional area (CSA) and degree of fat infiltration (FI) of the multifidus (MF) muscle and the erector spinae (ES) muscle were compared.

\section{Results}

There was no significant difference in demographic characteristics $(P>0.05)$ except for the bone mineral density $(B M D)(P<0.05)$ between the two groups. There were significant differences in the CSA and FI of the lower lumbar multifidus $(P<0.05)$. The CSA of the MF muscle at L3-L4, FI of the MF muscle at L4-L5 and L5-S1, and BMD were independent risk factors for ASD. Among patients who received two-segment fusion for the first time, significant difference was observed in the degree of FI of the MF muscle in the lower lumbar segment $(P<0.05)$.

\section{Conclusions}

The CSA, FI and BMD of the lower lumbar MF muscle are closely related to the occurrence of ASD. The CSA of the MF muscle at L3-L4, the degree of FI of the MF muscle at L4-L5 and L5-S1, and BMD were independent risk factors for ASD. The number of fusion segments in the first operation has a certain impact on the abovementioned conclusions.

\section{Background}

ASD after lumbar fusion is diagnosed by the imaging of the adjacent fusion segments and the presentation of corresponding clinical symptoms. With the extensive development of lumbar fusion surgery, scholars have conducted a series of studies on the risk factors of ASD. At present, the overall consensus is that age, sex, body mass index (BMI), spinal-pelvic balance parameters, the number of fusion segments in the first operation, surgical approach and so on are closely related to the occurrence of ASD [1-4]. 
In recent years, people have gradually found that the quantity and quality of the paraspinal muscles are important factors that lead to spinal diseases. At present, a large number of studies have defined the role of paraspinal muscle in low back pain, neurological function, proximal junctional kyphosis, physical function and so on [5-9]. The method for evaluating paraspinal muscles is to measure the CSA or FI of the selected cross-section of the muscles with the help of patients' MRI images to indirectly reflect the quantity and quality of the muscles.

However, there are few studies on the relationship between paraspinal muscles and ASD. Chang [10] et al. and Kim [11] et al. demonstrated that preoperative smaller CSA of the paraspinal muscle is a risk factor for postoperative ASD. However, in both studies, only a single level cross-section (L4-L5) was selected for muscle measurement. On the other hand, Duan [12] et al. used the Goutallier method to visually measure the paraspinal muscles' degree of FI and proved its connection with ASD. As the FI was not quantitatively evaluated, the accuracy may be low.

On the basis of previous studies, this study adopted the principle of 1:1 matching to conduct a casecontrol study. With the help of professional image analysis software, the CSA and FI of the paraspinal muscles at all lumbar intervertebral disc levels were quantitatively measured to explore whether the size and quality of the paraspinal muscles are risk factors for ASD after fusion.

\section{Methods}

\section{Subject population}

The ethics review committee of Huashan Hospital affiliated with Fudan University approved this singlecenter retrospective study. As the identity of the patients was anonymous, the requirement for an informed consent form was waived.

From May 2006 to September 2021, we included 67 patients who underwent posterior lumbar decompression, fusion and internal fixation because of ASD in our hospital; both operations were performed by the same surgical team in our hospital. The diagnostic criteria of ASD were as follows: imaging showed that the slippage of the vertebral body on lateral film was $\geq 4 \mathrm{~mm}$, the range of motion of the adjacent segments was more than $10^{\circ}$, and the loss of intervertebral disc height was more than $10 \%[13,14]$; MRI indicated that the modified Pfirrmann grade of the intervertebral disc [15] was grade IV or $\mathrm{V}$, or there was obvious intervertebral disc herniation and lumbar spinal canal stenosis at the adjacent segments; the corresponding clinical symptoms manifested based on the abovementioned imaging findings. The surgical indications of ASD were low back pain, nerve root symptoms and intermittent claudication, which seriously affected the quality of life, and there was no improvement after three months of conservative treatment. Exclusion criteria: 1. Lack of complete and clear MRI images before operation; 2. The follow-up period was less than 2 years; 3 . The number of fusion segments in the first operation was 3 or more. In the final case group, 34 cases were excluded, and 33 patients were included. Using a 1:1 matching method, 33 controls were matched according to sex, age at the time of operation, operation segment and follow-up time, selected from May 2006 to September 2021, patients who 
underwent posterior lumbar decompression, fusion and internal fixation in our department. The inclusion criteria of the control group were as follows: 1. Posterior lumbar decompression, fusion and internal fixation were performed in our hospital because of lumbar degenerative diseases; 2 . No secondary operation was performed on the lumbar vertebrae. The exclusion criteria were as follows: 1. Lack of complete and clear preoperative MRI images; 2. During the postoperative follow-up, the fusion adjacent segments showed obvious degeneration; 3 . The patients' clinical symptoms were significantly worse than those experienced after the previous operation.

\section{Lumber MRI scan acquisition}

The preoperative MRI images of the lumbar vertebrae were obtained by the following machines in the supine position: a 3T MRI scanner (Siemens Magnetom Verio, Erlangen, Germany). The imaging parameters were as follows: repetition time/echo time: 3,500/118 ms; slice thickness: $4 \mathrm{~mm}$; intersection gap: $0.4 \mathrm{~mm}$; matrix: $336 \times 384$; and field of view: $250 \mathrm{~mm}$.

The T2-weighted images of the median cross section of each intervertebral disc in the patient's L1-S1 were derived from a PACS workstation (Centricity Radiology RA100, GE Healthcare) in JPEG format, and the image information was deeply mined by image processing software (ImageJ, version 2, National Institutes of Health).

Referring to the previous method proposed by Hyun [16] et al, the area and gray value of the paraspinal muscles (MF muscle and ES muscle) in each patient were measured, and the average values were measured on the left and right sides. Using the ImageJ hand-drawn region of interest (ROI) function, we selected the MF muscle, ES muscle, intervertebral disc and subcutaneous fat on these five levels. The CSA of the paraspinal muscle/intervertebral disc CSA 100 was used as the relative CSA (rCSA) of the paraspinal muscle to eliminate the difference in body weight among different individuals, and the gray value of the paraspinal muscle/subcutaneous fat * 100 was used as the relative $\mathrm{FI}(\mathrm{rFI})$ to eliminate individual differences and quantitatively analyze the degree of fat infiltration (Fig. 1).

BMD was expressed as the CT value. The patients' lumbar CT images were found in the PACS system, the median cross-sectional images of the L1 and L2 vertebrae were selected, and an as-large-as-possible oval $\mathrm{ROI}$ was placed in front of the cancellous bone of the vertebral body. The average CT value of this area was read directly, and then the patient's bone mineral density was represented by the average value of the L1 and L2 measured data (Fig. 2).

To reduce measurement bias, each patient's images were measured twice by two experienced spinal surgeons in one week. Both intra-examiner reliability and inter-examiner reliability showed satisfactory consistency, with ICCs of 0.87 and 0.82 , respectively.

\section{Statistical analysis}


Data processing software (SPSS, version 23.0 for Windows, IBM) was used to analyze the data. For demographic data, the patient's age at the first operation, the time of follow-up and the CT value of vertebral cancellous bone before the first operation between ASD patients and controls were compared by independent sample $T$ test. The chi-squared test was used to compare the sex differences and specific surgical segments between the two groups. The rank sum test was used to compare the number of initial fusion segments between the two groups. Independent sample T test was used to compare the rCSA and the $\mathrm{rFI}$ of each segment of the multifidus and erector spinae muscle of the two groups before the first operation, and a univariate regression analysis was used to analyze the risk factors. $P<0.05$ was defined as a statistically significant difference.

\section{Results}

As shown in Table 1, the average age of the patient at the first operation in the 33 patients who underwent the second operation for ASD was $62.31 \pm 10.80$ years, while that of the control group was $62.9 \pm 10.73$ years. There was no significant difference between the two groups $(P>0.05)$. In addition, there was no significant difference in the ratio of males to females, the specific segment of the first fusion operation or the follow-up time between the two groups $(P>0.05)$. However, the CT value of vertebral cancellous bone in patients with ASD was significantly lower than that in the control group $(P<$ 0.05). 
Table 1

Demographic characteristics

\begin{tabular}{|llll|}
\hline Characteristic & $\begin{array}{l}\text { Patients with ASD } \\
(\mathbf{n}=33)\end{array}$ & $\begin{array}{l}\text { Control } \\
(\mathbf{n}=33)\end{array}$ & p-value \\
\hline Age at surgery ,year, mean \pm SD & $62.3 \pm 10.80$ & $62.9 \pm 10.73$ & 0.820 \\
\hline Gender, $n(\%)$ & & $14(42.4)$ & \\
\hline Male & $14(42.4)$ & $19(57.6)$ & \\
\hline Female & $19(57.6)$ & & 1.000 \\
\hline Number of fusion segments, $n(\%)$ & & $16(48.5)$ & \\
\hline 1 & $16(48.5)$ & $17(51.5)$ & \\
\hline 2 & $17(51.5)$ & & \\
\hline Initial fusion segment, $n(\%)$ & & $5(15.2)$ & \\
\hline L3-4 & $5(15.2)$ & $3(9.1)$ & \\
\hline L4-5 & $3(9.1)$ & $8(24.2)$ & \\
\hline L5-S1 & $8(24.2)$ & $7(21.2)$ & \\
\hline L3-5 & $7(21.2)$ & $10(30.3)$ & \\
\hline L4-S1 & $10(30.3)$ & $5.0(4.1)$ & \\
\hline Follow-up years, year, median(IQR) & $5.2(4.0)$ & $133.13 \pm 38.11$ & \\
\hline Bone density ,HU value ,mean \pm SD & $113.55 \pm 36.66$ & & \\
\hline Mean values are given as mean \pm SD. & & & \\
\hline *Statistical significance. & & & \\
\hline A P-value of < 0.05 was considered to indicate statistical significance. & & \\
\hline
\end{tabular}

Table 2 shows the rCSA of the paraspinal muscle at the median cross-sectional level of each intervertebral disc in the ASD group and the control group before the first operation. It can be seen from the table that there was no significant difference in the rCSA of the MF muscle between the two groups at L1-L2 and L2-L3. At L3-L4, L4-L5 and L5-S1, the rCSA of the MF muscle in the ASD group was lower than that in the control group, and the difference was statistically significant $(P<0.05)$. For the ES muscle, there was no significant difference in rCSA between the two groups at each segmental level. 
Table 2

Relative cross-sectional area (rCSA) for multifidus (MF) muscle and erector spinae (ES) muscle

\begin{tabular}{|c|c|c|c|c|}
\hline Level & Muscle & $\begin{array}{l}\text { Patients with ASD } \\
(n=33)\end{array}$ & $\begin{array}{l}\text { Control } \\
(n=33)\end{array}$ & P-value \\
\hline \multirow[t]{2}{*}{ L1-2 } & MF & $22.79 \pm 8.77$ & $21.50 \pm 7.65$ & 0.528 \\
\hline & ES & $117.05 \pm 18.92$ & $110.95 \pm 18.01$ & 0.185 \\
\hline \multirow[t]{2}{*}{ L2-3 } & MF & $28.79 \pm 10.88$ & $29.85 \pm 8.69$ & 0.663 \\
\hline & ES & $108.06 \pm 12.91$ & $105.77 \pm 10.65$ & 0.435 \\
\hline \multirow[t]{2}{*}{ L3-4 } & MF & $28.42 \pm 7.23$ & $32.52 \pm 7.76$ & $0.030 *$ \\
\hline & ES & $86.66 \pm 19.00$ & $85.23 \pm 22.18$ & 0.780 \\
\hline \multirow[t]{2}{*}{ L4-5 } & MF & $29.85 \pm 8.18$ & $34.54 \pm 6.60$ & $0.013^{\star}$ \\
\hline & ES & $71.38 \pm 13.77$ & $71.58 \pm 16.65$ & 0.958 \\
\hline \multirow[t]{2}{*}{ L5-S1 } & MF & $29.26 \pm 7.59$ & $34.21 \pm 9.41$ & $0.022^{\star}$ \\
\hline & ES & $51.18 \pm 20.73$ & $51.14 \pm 20.70$ & 0.993 \\
\hline \multicolumn{5}{|c|}{ The values are given as mean \pm SD. } \\
\hline \multicolumn{5}{|c|}{ *Statistical significance. } \\
\hline \multicolumn{5}{|c|}{ rCSA indicates relative cross-sectional area; ES, erector spinae; MF, multifidus } \\
\hline \multicolumn{5}{|c|}{ A P-value of $<0.05$ was considered to indicate statistical significance } \\
\hline
\end{tabular}

As shown in Table 3, there was no significant difference in the rFI of the MF muscle between the ASD group and the control group at L1-L2 and L2-L3. At L3-L4, L4-L5 and L5-S1, the rFI of the MF muscle in the ASD group was significantly higher than that in the control group $(P<0.05)$. There was no significant difference in the rFI of the ES muscle between the two groups $(P>0.05)$. 
Table 3

Relative fat infiltration ( $\mathrm{rFI}$ ) for multifidus (MF) muscle and erector spinae (ES) muscle

\begin{tabular}{|c|c|c|c|c|}
\hline Level & Muscle & $\begin{array}{l}\text { Patients with ASD } \\
(n=33)\end{array}$ & $\begin{array}{l}\text { Control } \\
(n=33)\end{array}$ & P-value \\
\hline \multirow[t]{2}{*}{ L1-2 } & MF & $35.05 \pm 8.94$ & $31.72 \pm 6.07$ & 0.082 \\
\hline & ES & $33.03 \pm 8.12$ & $30.98 \pm 7.27$ & 0.284 \\
\hline \multirow[t]{2}{*}{ L2-3 } & MF & $35.35 \pm 6.14$ & $32.64 \pm 5.83$ & 0.071 \\
\hline & ES & $31.86 \pm 6.36$ & $30.56 \pm 6.82$ & 0.426 \\
\hline \multirow[t]{2}{*}{ L3-4 } & MF & $38.97 \pm 6.01$ & $32.12 \pm 6.89$ & $<0.001^{*}$ \\
\hline & ES & $34.83 \pm 7.68$ & $31.60 \pm 6.84$ & 0.076 \\
\hline \multirow[t]{2}{*}{ L4-5 } & MF & $41.58 \pm 6.26$ & $32.07 \pm 7.13$ & $<0.001^{*}$ \\
\hline & ES & $36.59 \pm 8.55$ & $32.78 \pm 7.77$ & 0.062 \\
\hline \multirow[t]{2}{*}{ L5-S1 } & MF & $38.75 \pm 7.61$ & $32.93 \pm 6.51$ & $0.001^{*}$ \\
\hline & ES & $38.43 \pm 6.73$ & $36.56 \pm 8.38$ & 0.72 \\
\hline \multicolumn{5}{|c|}{ The values are given as mean \pm SD. } \\
\hline \multicolumn{5}{|c|}{ *Statistical significance. } \\
\hline \multicolumn{5}{|c|}{ rFl indicates relative fat infiltration; ES, erector spinae; MF, multifidus } \\
\hline A P-va & of $<0.05$ & vas considered to $i$ & ate statistical & nificanc \\
\hline
\end{tabular}

Then, the average values of BMD, rCSA and rFI of the MF at each level were calculated. If the patient's value is greater than the average, it is defined as a "high level", and vice versa as a "low level". Through univariate regression analysis, it was found that rCSA of the MF muscle at L3-L4 $(P=0.022, O R=0.166)$, rFI at L4-L5 $(P=0.005, O R=17.974)$, $r F I$ at L5-S1 $(P=0.024, O R=7.140)$ and $B M D(P=0.013, O R=0.081)$ were all risk factors for $\mathrm{ASD}$ (Table 4). 
Table 4

Risk Factors of the occurrence of ASD

\begin{tabular}{|llll|}
\hline \multicolumn{4}{|c|}{ Logistic Regression } \\
\hline Risk factor & p-Value & Odds ratio & $95 \%$ Confidence interval \\
\hline rCSA of MF at L 3-4 level & $0.022^{*}$ & 0.116 & $0.019-0.729$ \\
\hline rFI of MF at L 3-4 level & 0.337 & 0.406 & $0.064-2.562$ \\
\hline rCSA of MF at L 4-5 level & 0.427 & 0.475 & $0.076-2.985$ \\
\hline rFI of MF at L 4-5 level & $0.005^{*}$ & 17.974 & $2.349-137.505$ \\
\hline rCSA of MF at L 5-S1 level & 0.123 & 0.251 & $0.043-1.457$ \\
\hline rFI of MF at L5-S1 level & $0.024 *$ & 7.140 & $1.298-39.292$ \\
\hline Bone density & $0.013^{*}$ & 0.081 & $0.011-0.590$ \\
\hline *Statistical significance. & & & \\
\hline
\end{tabular}

rCSA indicates relative cross-sectional area; rFI indicates relative fat infiltration; ES, erector spinae; MF, multifidus

A P-value of $<0.05$ was considered to indicate statistical significance.

Interestingly, when comparing the MF muscle parameters of the two groups according to the segment of the first operation, we found that in the patients undergoing single segment surgery for the first time, the rCSA and $\mathrm{rFI}$ of the lower lumbar MF muscle in the ASD group were significantly different from those in the control group, while in the patients undergoing surgery in 2 segments for the first time, there was only a significant difference in the rFI of the MF muscle at L3-L4 and L4-L5 between the two groups (Table 5). 
Table 5

Comparison of MF characteristics in different levels between the ASD group and the control group when the initial operation segments were 1 and 2, respectively.

\begin{tabular}{|c|c|c|c|c|c|c|c|}
\hline & & Number of fus & n segmer & & Number of fu & on segme & $=2$ \\
\hline Level & Characteristic & $\begin{array}{l}\text { Patients with } \\
\text { ASD }\end{array}$ & Control & $\begin{array}{l}\mathrm{p}- \\
\text { value }\end{array}$ & $\begin{array}{l}\text { Patients with } \\
\text { ASD }\end{array}$ & Control & $\begin{array}{l}\mathrm{p}- \\
\text { value }\end{array}$ \\
\hline L1-2 & rCSA & $21.50 \pm 11.61$ & $\begin{array}{l}20.91 \pm \\
8.51\end{array}$ & 0.874 & $23.65 \pm 5.85$ & $\begin{array}{l}22.05 \pm \\
7.47\end{array}$ & 0.506 \\
\hline & $\mathrm{rFI}$ & $34.38 \pm 9.26$ & $\begin{array}{l}31.46 \pm \\
6.84\end{array}$ & 0.335 & $35.40 \pm 9.41$ & $\begin{array}{l}31.62 \pm \\
5.70\end{array}$ & 0.179 \\
\hline L2-3 & rCSA & $25.48 \pm 12.54$ & $\begin{array}{l}26.20 \pm \\
6.87\end{array}$ & 0.847 & $31.12 \pm 8.98$ & $\begin{array}{l}32.64 \pm \\
9.53\end{array}$ & 0.647 \\
\hline & $\mathrm{rFI}$ & $34.20 \pm 7.43$ & $\begin{array}{l}30.94 \pm \\
5.88\end{array}$ & 0.193 & $35.92 \pm 5.02$ & $\begin{array}{l}34.16 \pm \\
5.78\end{array}$ & 0.364 \\
\hline L3-4 & rCSA & $25.09 \pm 6.21$ & $\begin{array}{l}32.52 \pm \\
9.39\end{array}$ & $0.016^{*}$ & $30.41 \pm 7.00$ & $\begin{array}{l}32.17 \pm \\
6.71\end{array}$ & 0.474 \\
\hline & $\mathrm{rFI}$ & $37.49 \pm 7.02$ & $\begin{array}{l}29.12 \pm \\
6.89\end{array}$ & $0.003^{\star}$ & $40.22 \pm 5.19$ & $\begin{array}{l}35.82 \pm \\
4.81\end{array}$ & $0.019 *$ \\
\hline L4-5 & rCSA & $26.23 \pm 8.41$ & $\begin{array}{l}34.54 \pm \\
6.92\end{array}$ & $0.006^{*}$ & $33.43 \pm 6.91$ & $\begin{array}{l}34.81 \pm \\
6.79\end{array}$ & 0.571 \\
\hline & $\mathrm{rFI}$ & $39.23 \pm 6.29$ & $\begin{array}{l}30.51 \pm \\
7.14\end{array}$ & $0.001 *$ & $43.77 \pm 5.97$ & $\begin{array}{l}33.99 \pm \\
6.40\end{array}$ & $<.001^{\star}$ \\
\hline $\begin{array}{l}\text { L5- } \\
\text { S1 }\end{array}$ & rCSA & $29.32 \pm 8.29$ & $\begin{array}{l}37.82 \pm \\
8.83\end{array}$ & $0.011^{*}$ & $29.61 \pm 7.58$ & $\begin{array}{l}31.34 \pm \\
8.84\end{array}$ & 0.556 \\
\hline & $\mathrm{rFI}$ & $38.43 \pm 5.67$ & $\begin{array}{l}31.20 \pm \\
5.11\end{array}$ & $0.001^{\star}$ & $39.45 \pm 9.50$ & $\begin{array}{l}34.01 \pm \\
7.49\end{array}$ & 0.082 \\
\hline The va & s are given as & ean \pm SD & & & & & \\
\hline *Stat & al significance & & & & & & \\
\hline $\begin{array}{l}\text { rCSA i } \\
\text { multifi }\end{array}$ & $\begin{array}{l}\text { cates relative } \\
\mathrm{s}\end{array}$ & ss-sectional & $\mathrm{rFl}$ ind & relati & at infiltration & erecto & ae; MF, \\
\hline$A P-v$ & of $<0.05$ was & nsidered to & e sta & sign & ce. & & \\
\hline
\end{tabular}

\section{Discussion}

With the increasing development and popularity of fusion surgery, the incidence of clinically diagnosed ASD is common. Some studies have shown that the incidence of ASD is between $4 \%$ and $31 \%[17,18]$. Therefore, scholars have performed in depth research on the risk factors for ASD with intentions to 
prevent its development, improve the patient's quality of life after surgery and avoid the pain of secondary operations.

In recent years, an increasing number of studies have focused on the relationship between paraspinal muscles and spinal diseases. This is reasonable because the paraspinal muscle itself is connected with the bony structure, can support the body to complete many activities, and is a very important anatomical structure of surgical approach, therefore details cannot be ignored. At present, there is a lack of a unified method for evaluating the quality and quantity of the paraspinal muscles. It is common to use CSA to indirectly reflect the number of the paraspinal muscles, while FI or functional CSA is used to reflect the quality of paraspinal muscles [19.20]. Previous studies have proven the relationship between the paraspinal muscle and low back pain, neurological function, proximal junctional kyphosis, physical activity, etc. However, due to the disunity of different measurement methods, research results obtained from different centers sometimes greatly differ and even draw contradictory conclusions. Recently, some scholars began to study the relationship between paraspinal muscles and ASD [10-12]. However, the study has obvious limitations: it may be inappropriate to select only the cross section of the paraspinal muscles at the single segment level to represent the overall paraspinal muscle level because there is no known basic research [21-24] or theoretical support, and there may be poor comparability between different individuals at the same level due to factors such as development, living habits, pathological changes and so on. The accuracy of the FI measurement may be insufficient due to mainly relying on hand-drawn ROI or visual measurement. Based on this, this study measured the cross-sectional parameters of the paraspinal muscles at each level of the lumbar intervertebral disc, and the degree of $\mathrm{FI}$ was expressed by the "gray value" parameter with the help of professional image processing software.

Compared with the demographic data between the selected ASD patients and the control group, there was a statistically significant difference in BMD between the two groups. This is consistent with the results of previous studies [25]. In this study, the CT value of the cancellous area of the vertebral body was obtained to represent the patient's BMD. Previous studies have confirmed that the CT value of vertebral cancellous bone is positively correlated with the actual patient's BMD [26], therefore, it is feasible to compare and analyze the CT value. The reason for this difference may be that patients with a lower BMD are more likely to have bone degeneration, destruction and spinal imbalance, and these patients have a higher risk of developing ASD than their peers after the first operation. This is consistent with previous perceptions that BMD is an important indicator that must be considered in patients undergoing spinal surgery at any stage.

We compared and analyzed the paraspinal muscle parameters of each intervertebral disc level (L1-S1) between the two groups. The results showed that there were significant differences in the rCSA and rFI of the MF muscle at the lower lumbar level between the two groups, but there was no significant difference in the quality and quantity of the ES muscle at each segmental level. This result confirms the important role of MF muscle in the development of ASD in patients, and the MF muscle at the lower lumbar level is more representative of the characteristics of the whole muscle. Then, we used univariate regression analysis to confirm that the smaller CSA of the MF muscle at L3-L4, the greater degree of Fl at L4-L5 and 
L5-S1, and the lower BMD were all risk factors for ASD. It is worth noting that previous studies have shown a correlation between BMD and the degree of paraspinal muscle FI [27-29]. However, this correlation is not reflected in this study, considering that all subjects included in this study are patients with lumbar degenerative diseases, which is different from the normal people in previous studies.

Previous scholars have confirmed the effect of the number of segments in the first operation on the development of ASD [30-32]. We tried to divide all the patients into two groups according to the segment of the first operation and found that there were significant differences in the CSA and the degree of FI of the lower lumbar MF muscle between the two groups in the patients receiving single segment surgery for the first time. In the patients who received two-segment fusion for the first time, there was only a difference in the $\mathrm{Fl}$ of the lower lumbar MF muscle between the two groups, but there was no difference in the CSA between the two groups. This may be because the longer fusion segment itself is a risk factor for the occurrence of ASD; on this basis, early changes in the paraspinal muscles can lead to the occurrence of ASD. Therefore, it can be considered that the $\mathrm{FI}$ of paraspinal muscles can reflect the changes in muscle characteristics more sensitively than the CSA. In actual clinical work in the future, it may be possible to directly determine the degree of FI of the lower lumbar MF muscle through intelligent image analysis software, which can be used as an evaluation index.

This study revealed the role of paraspinal muscles in the development of ASD. First, to prevent the occurrence of ASD, spinal surgeons should have a long-term vision, and the state of paraspinal muscles should also be taken into consideration when making surgical plans. Second, we should continue to emphasize the importance of low back muscle exercise and even set up a systematic exercise program for patients after the first lumbar fusion. Previous prospective studies on other spinal diseases have also shown that low back muscle exercise can effectively improve muscle quality [33-35].

This study also has some limitations. The sample size of this study was small, and there were only 33 cases in the ASD group. This is because there is a requirement for high-quality image data before the first operation. These images must be collected in this research center, hence limiting the number of sample size. In this study, all the segmental levels of each patient's muscles were measured, compared and analyzed, which could have compensated, to a certain degree, for the small sample size. In addition, previous studies have shown that spinal-pelvic sagittal imbalance is also one of the risk factors for ASD $[36,37]$. However, due to the overall lack of full-length films of the spine in our center, the measurement of pelvic parameters is limited.

\section{Conclusions}

The CSA and FI of the lower lumbar MF muscle and BMD before the first operation are closely related to the occurrence of ASD after lumbar fusion. The CSA of the MF muscle at L3-L4, the FI of the MF muscle at L4-L5 and L5-S1, and BMD were independent risk factors for the development of ASD. The number of fusion segments in the first operation has a certain impact on the abovementioned conclusions, so the specific impact of the number of different fusion segments needs to be further studied. 


\section{Abbreviations}

ASD

Adjacent segment disease

CSA

Cross-sectional area

$\mathrm{FI}$

Fat infiltration

MF

Multifidus

ES

Erector spinae

BMD

Bone mineral density

BMI

Body mass index

rCSA

Relative ross-sectional area

$\mathrm{rFI}$

Relative fat infiltration

\section{Declarations}

\section{Ethics approval and consent to participate}

The ethics review committee of Huashan Hospital affiliated with Fudan University approved this singlecenter retrospective study (file no. 2021M-011). As the identity of the patients was anonymous, the requirement for an informed consent form was waived.

\section{Consent for publication}

The images used in this article are from a 65-year-old man whose consent for publication has been obtained.

\section{Availability of data and materials}

The datasets used and/or analysed during the current study are available from the corresponding author on reasonable request

\section{Competing interests}

The authors declare that they have no competing interests. 


\section{Funding}

Advanced and appropriate Technology Popularization Project of Shanghai Health Commission, 2019SY023

\section{Authors' contributions}

XS Ma, HL Wang and F Zou conceived and designed the study. ZY Gong, DC Li and SY Liu wrote the paper. XS Ma, ZY Gong, Dachuan Li collected patients' data. ZY Gong and HL Wang did the data analysis. All authors read and approved the final manuscript.

\section{Acknowledgements}

Not applicable.

\section{Authors' information}

All the authors are from Department of Othorpaedics, Huashan Hospital, Fudan University , Shanghai, China. The address is No. 12 Urumqi middle road, Jing'an district, Shanghai, China. Correspondence information:

1. Ma Xiaosheng

Address: No. 12 Urumqi middle road, Jing'an district, Shanghai, China

Telephone Number: 021-52887134

E-mail address: dr_maxiaosheng@126.com

2. Wang Hongli

Address: No. 12 Urumqi middle road, Jing'an district, Shanghai, China

Telephone Number: 021-52887134

E-mail address: wanghongli0212@163.com

\section{References}

1. Kumar MN, Baklanov A, Chopin D. Correlation between sagittal plane changes and adjacent segment degeneration following lumbar spine fusion. Eur Spine J. 2001;10(4):314-9.

2. Lai PL, Chen LH, Niu CC, Fu TS, Chen WJ. Relation between laminectomy and development of adjacent segment instability after lumbar fusion with pedicle fixation. Spine (Phila Pa 1976). 2004;29(22):2527-32; discussion 32. 
3. Wang H, Ma L, Yang D, Wang T, Liu S, Yang S, et al. Incidence and risk factors of adjacent segment disease following posterior decompression and instrumented fusion for degenerative lumbar disorders. Medicine (Baltimore). 2017;96(5):e6032.

4. Fukaya K, Hasegawa M, Shirato M, Teshima T. [Risk Factors for Predicting the Need for Additional Surgery for Symptomatic Adjacent Segment Disease after Minimally Invasive SurgeryTransforaminal Lumbar Interbody Fusion]. No Shinkei Geka. 2017;45(4):311-9.

5. Goubert D, Oosterwijck JV, Meeus M, Danneels L. Structural Changes of Lumbar Muscles in Nonspecific Low Back Pain: A Systematic Review. Pain Physician. 2016;19(7):E985-e1000.

6. Wan Q, Lin C, Li X, Zeng W, Ma C. MRI assessment of paraspinal muscles in patients with acute and chronic unilateral low back pain. Br J Radiol. 2015;88(1053):20140546.

7. Sions JM, Smith AC, Hicks GE, Elliott JM. Trunk Muscle Size and Composition Assessment in Older Adults with Chronic Low Back Pain: An Intra-Examiner and Inter-Examiner Reliability Study. Pain Med. 2016;17(8):1436-46.

8. Hyun SJ, Kim YJ, Rhim SC. Patients with proximal junctional kyphosis after stopping at thoracolumbar junction have lower muscularity, fatty degeneration at the thoracolumbar area. Spine J. 2016;16(9):1095-101.

9. Cuellar WA, Wilson A, Blizzard CL, Otahal P, Callisaya ML, Jones G, et al. The assessment of abdominal and multifidus muscles and their role in physical function in older adults: a systematic review. Physiotherapy. 2017;103(1):21-39.

10. Chang MY, Park Y, Ha JW, Zhang HY, Lee SH, Hong TH, et al. Paraspinal Lean Muscle Mass Measurement Using Spine MRI as a Predictor of Adjacent Segment Disease After Lumbar Fusion: A Propensity Score-Matched Case-Control Analysis. AJR Am J Roentgenol. 2019:1-8.

11. Kim JY, Ryu DS, Paik HK, Ahn SS, Kang MS, Kim KH, et al. Paraspinal muscle, facet joint, and disc problems: risk factors for adjacent segment degeneration after lumbar fusion. Spine J. 2016;16(7):867-75.

12. Duan PG, Mummaneni PV, Guinn JMV, Rivera J, Berven SH, Chou D. Is the Goutallier grade of multifidus fat infiltration associated with adjacent-segment degeneration after lumbar spinal fusion? J Neurosurg Spine. 2020:1-6.

13. Cheh G, Bridwell KH, Lenke LG, Buchowski JM, Daubs MD, Kim Y, et al. Adjacent segment disease followinglumbar/thoracolumbar fusion with pedicle screw instrumentation: a minimum 5-year follow-up. Spine (Phila Pa 1976). 2007;32(20):2253-7.

14. Min JH, Jang JS, Lee SH. Comparison of anterior- and posterior-approach instrumented lumbar interbody fusion for spondylolisthesis. J Neurosurg Spine. 2007;7(1):21-6.

15. Pfirrmann CW, Metzdorf A, Zanetti M, Hodler J, Boos N. Magnetic resonance classification of lumbar intervertebral disc degeneration. Spine (Phila Pa 1976). 2001;26(17):1873-8.

16. Hyun SJ, Bae CW, Lee SH, Rhim SC. Fatty Degeneration of the Paraspinal Muscle in Patients With Degenerative Lumbar Kyphosis: A New Evaluation Method of Quantitative Digital Analysis Using MRI and CT Scan. Clin Spine Surg. 2016;29(10):441-7. 
17. Okuda S, Nagamoto Y, Matsumoto T, Sugiura T, Takahashi Y, Iwasaki M. Adjacent Segment Disease After Single Segment Posterior Lumbar Interbody Fusion for Degenerative Spondylolisthesis: Minimum 10 Years Follow-up. Spine (Phila Pa 1976). 2018;43(23):E1384-e8.

18. Bydon M, Macki M, Kerezoudis P, Sciubba DM, Wolinsky JP, Witham TF, et al. The incidence of adjacent segment disease after lumbar discectomy: A study of 751 patients. J Clin Neurosci. 2017;35:42-6.

19. Elliott JM, Kerry R, Flynn T, Parrish TB. Content not quantity is a better measure of muscle degeneration in whiplash. Man Ther. 2013;18(6):578-82.

20. Elliott JM, Pedler AR, Jull GA, Van Wyk L, Galloway GG, O'Leary SP. Differential changes in muscle composition exist in traumatic and nontraumatic neck pain. Spine (Phila Pa 1976). 2014;39(1):3947.

21. Hodges PW, Galea MP, Holm S, Holm AK. Corticomotor excitability of back muscles is affected by intervertebral disc lesion in pigs. Eur J Neurosci. 2009;29(7):1490-500.

22. Bailey JF, Miller SL, Khieu K, O'Neill CW, Healey RM, Coughlin DG, et al. From the international space station to the clinic: how prolonged unloading may disrupt lumbar spine stability. Spine J. 2018;18(1):7-14.

23. Li YP, Schwartz RJ, Waddell ID, Holloway BR, Reid MB. Skeletal muscle myocytes undergo protein loss and reactive oxygen-mediated NF-kappaB activation in response to tumor necrosis factor alpha. Faseb j. 1998;12(10):871-80.

24. James G, Sluka KA, Blomster L, Hall L, Schmid AB, Shu CC, et al. Macrophage polarization contributes to local inflammation and structural change in the multifidus muscle after intervertebral disc injury. Eur Spine J. 2018;27(8):1744-56.

25. Etebar S, Cahill DW. Risk factors for adjacent-segment failure following lumbar fixation with rigid instrumentation for degenerative instability. J Neurosurg. 1999;90(2 Suppl):163-9.

26. Lee S, Chung CK, Oh SH, Park SB. Correlation between Bone Mineral Density Measured by DualEnergy X-Ray Absorptiometry and Hounsfield Units Measured by Diagnostic CT in Lumbar Spine. J Korean Neurosurg Soc. 2013;54(5):384-9.

27. Zhao Y, Huang M, Serrano Sosa M, Cattell R, Fan W, Li M, et al. Fatty infiltration of paraspinal muscles is associated with bone mineral density of the lumbar spine. Arch Osteoporos. 2019;14(1):99.

28. He H, Liu Y, Tian Q, Papasian CJ, Hu T, Deng HW. Relationship of sarcopenia and body composition with osteoporosis. Osteoporos Int. 2016;27(2):473-82.

29. Miyakoshi N, Hongo M, Mizutani Y, Shimada Y. Prevalence of sarcopenia in Japanese women with osteopenia and osteoporosis. J Bone Miner Metab. 2013;31(5):556-61.

30. Ghiselli G, Wang JC, Bhatia NN, Hsu WK, Dawson EG. Adjacent segment degeneration in the lumbar spine. J Bone Joint Surg Am. 2004;86(7):1497-503.

31. Park JY, Chin DK, Cho YE. Accelerated L5-S1 Segment Degeneration after Spinal Fusion on and above L4-5: Minimum 4-Year Follow-Up Results. J Korean Neurosurg Soc. 2009;45(2):81-4. 
32. Lee CS, Hwang CJ, Lee SW, Ahn YJ, Kim YT, Lee DH, et al. Risk factors for adjacent segment disease after lumbar fusion. Eur Spine J. 2009;18(11):1637-43.

33. Katzman WB, Vittinghoff E, Lin F, Schafer A, Long RK, Wong S, et al. Targeted spine strengthening exercise and posture training program to reduce hyperkyphosis in older adults: results from the study of hyperkyphosis, exercise, and function (SHEAF) randomized controlled trial. Osteoporos Int. 2017;28(10):2831-41.

34. Ceballos Laita L, Tejedor Cubillo C, Mingo Gómez T, Jiménez Del Barrio S. Effects of corrective, therapeutic exercise techniques on adolescent idiopathic scoliosis. A systematic review. Arch Argent Pediatr. 2018;116(4):e582-e9.

35. Bansal S, Katzman WB, Giangregorio LM. Exercise for improving age-related hyperkyphotic posture: a systematic review. Arch Phys Med Rehabil. 2014;95(1):129-40.

36. Djurasovic MO, Carreon LY, Glassman SD, Dimar JR, 2nd, Puno RM, Johnson JR. Sagittal alignment as a risk factor for adjacent level degeneration: a case-control study. Orthopedics. 2008;31(6):546.

37. Park JY, Cho YE, Kuh SU, Cho JH, Chin DK, Jin BH, et al. New prognostic factors for adjacent-segment degeneration after one-stage 360 degrees fixation for spondylolytic spondylolisthesis: special reference to the usefulness of pelvic incidence angle. J Neurosurg Spine. 2007;7(2):139-44.

\section{Figures}

\section{Figure 1}

The outline of the Intervertebral disc (A), multifidus muscle (B), erector spinae muscle (C) and subcutaneous fat (D) are represented by hand-drawn region of interest using Image $\mathrm{J}$.

\section{Figure 2}

Place an as-large-as-possible oval ROI in the cancellous tissue of the vertebral body, and read out the average $\mathrm{CT}$ value of this area directly to indicate the bone mineral density of the patient.

\section{Supplementary Files}

This is a list of supplementary files associated with this preprint. Click to download.

- Additionalfile1.xlsx 